\title{
NGHIÊN CỬU ĐẶC ĐIỂM TỔN THƯƠNG MÔ BỆNH HỌC TRONG BỆNH CẦU THẬN TRẺ EM
}

Nguyễ̂ Thị Hồng Đức ${ }^{1}$, Trần Kiêm Hảo ${ }^{1}$, Nguyễn Thị Diễm Chi ${ }^{1}$, Nguyễn Đình Cân ${ }^{I}$, Nguyễn Hoàng Minh ${ }^{1}$, Huỳnh Ngọc Linh ${ }^{2}$, Phạm Nguyên Cuờng

1. Bệnh viện Trung ưong Huế;

DOI: $10.47122 /$ vjde.2020.43.11

\section{ABSTRACT \\ Study histopathological findings in childhood glomerular disease}

Objective: This study aims to evaluate histopathological findings in childhood glomerular disease. Method: This cross sectional study conducted 32 glomerular diseases patients who were performed renal biopsy from 2016 to 2019. Results: Mean age was $10,28 \pm 3,06$ (the lowest age was 4 ). The most frequent indications for kidney biopsy were: steroid resistant nephrotic syndrome and systemic lupus erythematosus with renal involvement $\quad(34,4 \%$ and $21,9 \%$, respectively). Minimal Change Disease was the most common types of biopsy-proven glomerular diseases $15 / 32(46,9 \%)$, next to was lupus nephritis type IV $12,5 \%$, IgA nephropathy $12,5 \%$ and FSGS $9,4 \%$, lupus nephritis type III 6,3\%. Conclusion: Steroid resistant nephrotic syndrome was the most frequent indication of kidney biopsy. And Minimal Change Disease was the most common biopsy proven glomerular disease.

Key words: glomerular diseases, kidney (renal) biopsy, renal histopathology

\section{TÓM TẮT}

Muc tiêu: Đánh giá tổn thương mô bệnh học các bệnh cầu thận trẻ em. Phương pháp nghiên cứu: Mô tả cắt ngang. Kêt quả: Nghiên cứu 32 trẻ có bệnh lý cầu thận có chỉ định sinh thiết thận, có tuổi trung bình 10,28 $\pm 3,06$, (nhỏ nhất 4 tuổi). Chỉ định sinh thiết thận nhiều nhất là hội chứng thận hư kháng corticoid $34,4 \%$, tiếp đến là lupus ban đỏ có tổn thương thận chiếm $21,9 \%$. Về kết quả sinh thiết, tổn thương tối thiểu chiếm tỉ lệ cao nhất $46,9 \%$, tiếp đến là tổn thương viêm thận lupus nhóm IV và bệnh thận $\operatorname{IgA}(12,5 \%)$, xơ hóa cầu thận từng phần khu trú $(9,4 \%)$, viêm thận lupus III 6,3\%. Kết luận: Tổn thương tối thiểu là thường gặp nhất trong sinh thiết các bệnh cầu thận và chỉ định sinh thiết thận phổ biến là hội chứng thận hư kháng corticoid.

Tù khoá: bệnh cầu thận, sinh thiết thận, mô bệnh học thận.

Chịu trách nhiệm chính: Trần Kiêm

HảoNgày nhận bài: 27/10/2020

Ngày phản biện khoa học: 01/11/2020

Ngày duyệt bài: 12/12/2020

Email: drhaonhi@gmail.com

Điện thoại: 0914002329

\section{1. ĐẠT VẤN ĐỀ}

Bệnh cầu thận là một trong những nguyên nhân phổ biến trong bệnh lý thận trẻ em. Bệnh lý này chiếm khoảng $14 \%$ bệnh lý thận mạn và khoảng $15-29 \%$ bệnh thận giai đoạn cuối ở trẻ em[2]. Phổ bệnh lý cầu thận bao gồm hội chứng thận hư và hội chứng thận viêm[7]. Trên lâm sàng, việc chẩn đoán và điều trị chủ yếu dựa vào khai thác bệnh sử, thăm khám và một số xét nghiệm cơ bản. Tuy nhiên, vẫn có nhiều trường hợp chẩn đoán lâm sàng chưa rõ cần phải dựa vào tổn thương trên mô bệnh học để xác định. Sinh thiết thận trong bệnh lý cầu thận là kĩ thuật cần thiết để đánh giá tổn thương mô bệnh học góp phần giúp chẩn đoán điều trị và tiên lượng bệnh tốt hơn.

Trên thế giới, mặc dù sinh thiết thận đã được phổ biến cho chẩn đoán bệnh lý thận ở người lớn nhưng vẫn không phải là thủ thuật phổ biến ở trẻ em. Gần đây kỹ thuật sinh thiết đã cải tiến đã an toàn hơn, được khuyên dùng hơn trong chẩn đoán bệnh nhi[4]. Tại Việt Nam, các nghiên cứu ứng dụng sinh thiết thận trong chẩn đoán các bệnh cầu thận trẻ em đã 
được thực hiện ở hai đầu đất nước từ năm 2006 [3]. Tuy nhiên, tại miền Trung vẫn chưa có nghiên cứu được công bố về sinh thiết thận ở trẻ em. Do đó, chúng tôi làm đề tài này nhằm đánh giá các tổn thương mô bệnh học trên sinh thiết thận và so sánh giữa hình ảnh tổn thương mô bệnh học và lâm sàng của trẻ có bệnh lý cầu thận tại Bệnh viện Trung ương Huế.

\section{2. ĐỐI TƯợNG VÀ PHƯƠNG PHÁP NGHIÊN CÚ'U}

2.1. Đối tượng nghiên cứu: 32 bệnh nhiđến khám và điều trị tại Trung Tâm Nhi, Bệnh viện Trung ương Huế từ tháng 1/2016 đến 6/2019 với biểu hiện lâm sàng bệnh lý cầu thậncó chỉ định sinh thiết thận.

\subsubsection{Tiêu chuẩn chọn bệnh}

Chỉ định sinh thiết thận

2.1.1.1. Hội chứng thận hư

- Hội chứng thận hư kháng corticoid: không đáp ứng với Prednisolon liều $2 \mathrm{mg} / \mathrm{kg}$ / ngày sau 6-8 tuần điều trị).

- Hội chứng thận hư phụ thuộc corticoid liều cao ( $>1 \mathrm{mg} / \mathrm{kg} /$ ngày).

- Hội chứng thận hư không đơn thuần hoặc có liên quan đển bệnh hệ thống.

2.1.1.2. Hội chứng viêm cầu thận cấp có

- Thận hư - thận viêm; Tiểu máu đại thể hoặc tăng huyết áp hơn 3 tuần.

- Suy thận cấp tiến triển nhanh hoặc suy thận cấp không về bình thường sau 2-3 tuần.

- Bổ thể C3 giảm kéo dài sau 8 tuần.

2.1.1.3. Lupus ban đỏ tổn thương thận (protein niệu $>0,5 \mathrm{~g} / 1,73 \mathrm{~m}^{2} /$ ngày)

- Đạm niệu tăng $\geq 1 \mathrm{~g} / 1,73 \mathrm{~m}^{2} /$ ngày.

- Đạm niệu tăng $\geq 0,5 \mathrm{~g} / 1,73 \mathrm{~m}^{2} /$ ngày và $\geq 5$ hồng cầu/vi trường.
- Đạm niệu tăng $\geq 0,5 \mathrm{~g} / 1,73 \mathrm{~m}^{2} /$ ngày và trụ tế bào $(+)$.

- Tăng creatinine máu không do sốc, giảm thể tích máu hay do thuốc. Hoặc đạm niệu còn cao $>0,3-1 \mathrm{~g} / 1,73 \mathrm{~m}^{2} /$ ngày sau khi liệu trình điều trị Lupus hoạt động

2.1.1.4. Tiểu máu vi thể

- Kéo dài trên 12 tháng.

- Có tiểu đạm $>1 \mathrm{~g} / 1,73 \mathrm{~m}^{2} /$ ngày.

- Tiểu máu có tính gia đình.

2.1.1.5. Tiểu máu đại thể tái phát trên 3 lần.

2.1.1.6. Các trường hợp suy thận cấp chưa rõ nguyên nhân có kích thước thận bình thường [5].

\subsubsection{Tiêu chuẩn loại trù̀}

- Bệnh nhi và người nhà không đồng ý.

- Không nằm trong chỉ định sinh thiết thận.

- Các mẫu sinh thiết có số cầu thận dưới 5.

\subsubsection{Cách tiến hành}

Tất cả bệnh nhân được tiến hành sinh thiết dưới hướng dẫn siêu âm bằng súng sinh thiết. Các mẫu được chuyển đi bệnh viện Nhi Đồng I và bệnh viện Việt Đức để đọc kết quả.

Các phân loại giải phẫu bệnh các bệnh cầu thận:

- Bệnh lupus ban đỏ: theo Hiệp hội thận học thế giới/Hiệp hội giải phẫu bệnh thận (INS/RPS) năm 2004.

- Hội chứng thận hư: dựa trên phân loại của ISKDC (International Study of Kidney Diseases in Children)

- Bệnh thận IgA: theo phân loại Oxford 2009.

- Các bệnh lý cầu thận khác: theo tài liệu Hepstintal

2.2. Phương pháp nghiên cứu: Mô tả cắt ngang.

2.3. Xử lý và phân tích dữ liệu: SPSS 20

\section{KÊTT QUẢ NGHIÊN CÚU}

\section{1. Đặc điểm chung}

Tuổi trung bình của nhóm nghiên cứu10,28 $\pm 3,06$, tuổi nhỏ nhất 4 tuổi và lớn nhất 15 tuổi.

Bảng 1. Nhóm tuổi

\begin{tabular}{|c|c|c|}
\hline Nhóm tuổi & n & \% \\
\hline$<=5$ tuổi & 2 & 6,3 \\
\hline $6-10$ tuồi & 14 & 43,7 \\
\hline $11-15$ tuổi & 16 & 50,0 \\
\hline Tổng & 32 & 100 \\
\hline
\end{tabular}


Nhóm tuổi từ 11-15 tuổi chiếm tỉ lệ cao nhất 50\%

Bảng 2. Giới

\begin{tabular}{|c|c|c|}
\hline Giới & n & \% \\
\hline Nữ & 11 & 34,5 \\
\hline Nam & 21 & 65,5 \\
\hline Tổng & 32 & 100 \\
\hline
\end{tabular}

Nam nhiều hơn nữ với tỉ lệ là1,9:1.

\section{2. Đặc điểm lâm sàng}

Bảng 3. Triệu chứng lâm sàng thường gặp

\begin{tabular}{|l|c|c|}
\hline \multicolumn{1}{|c|}{ Triệu chứng } & Bệnh nhân (n) & Tỉ lệ (\%) \\
\hline Phù & 24 & 75,0 \\
\hline Tăng huyết áp & 10 & 31,3 \\
\hline Thiểu niệu & 7 & 21,9 \\
\hline Đái máu đại thể & 9 & 28,1 \\
\hline Viêm hô hấp trên & 6 & 18,8 \\
\hline Đau khớp & 3 & 9,4 \\
\hline Ban da & 7 & 21,9 \\
\hline Không có triệu chứng kèm theo & 2 & 6,3 \\
\hline
\end{tabular}

Triệu chứng lâm sàng thường gặp lúc vào viện nhất là phù(75\%), tiếp đến là tăng huyết áp $31,3 \%$ và đái máu $(28,1 \%)$. Tỉ lệ bệnh không có triệu chứng $(6,3 \%)$.

Bảng 4. Chẩn đoán lâm sàng trước sinh thiết.

\begin{tabular}{|l|c|c|}
\hline \multicolumn{1}{|c|}{ Chẩn đoán trước sinh thiết } & $\mathbf{n}$ & $\mathbf{\%}$ \\
\hline Hội chứng thận hư & 15 & 46,9 \\
\hline Viêm cầu thận cấp & 5 & 15,6 \\
\hline Lupus ban đỏ & 7 & 21,9 \\
\hline Đái máu tái diễn & 4 & 12,5 \\
\hline Suy thận chưa rõ nguyên nhân & 1 & 3,1 \\
\hline \multicolumn{1}{|c|}{ Tổng } & 32 & 100 \\
\hline
\end{tabular}

Chẩn đoán chính trước sinh thiếtvẫn là hội chứng thận hư chiếm 46,9\%.

Bảng 5. Chỉ định sinh thiết thận.

\begin{tabular}{|l|c|c|}
\hline \multicolumn{1}{|c|}{ Chỉ định } & n & \% \\
\hline HCTH kháng corticoid & 11 & 34,4 \\
\hline HCTH phụ thuộc corticoid & 4 & 12,5 \\
\hline Lupus ban đỏ & 7 & 21,9 \\
\hline VCTCcó suy thận & 2 & 6,3 \\
\hline VCTC đái máu đại thể & 3 & 9,4 \\
\hline Đái máu tái diễn & 4 & 12,5 \\
\hline Suy thận chưa rõ nguyên nhân & 1 & 3,1 \\
\hline \multicolumn{1}{|c|}{ Tổng } & 32 & 100 \\
\hline
\end{tabular}

(*) HCTH: hội chứng thận hư; VCTC: viêm cầu thận cấp

Chỉ định sinh thiết thận nhiều nhất là hội chứng thận hư kháng corticoid $(34,3 \%)$, tiếp đến 
lupus ban đỏ (21,9\%). 2 trường hợp VCTC có suy thận $(6,3 \%)$ và 1 trường hợp suy thận chưa rõ nguyên nhân cần làm sinh thiết.

\subsection{Chẩn đoán giải phẫu bệnh sau sinh thiết}

Bảng 6. Chẩn đoán giải phẫu bệnh sau sinh thiết.

\begin{tabular}{|l|c|c|}
\hline \multicolumn{1}{|c|}{ Kết quả sinh thiết } & n & \% \\
\hline MCD & 15 & 46,9 \\
\hline FSGS & 3 & 9,4 \\
\hline MPGN & 1 & 3,1 \\
\hline Xơ hóa toàn bộ & 1 & 3,1 \\
\hline Viêm thận lupus III & 2 & 6,3 \\
\hline Viêm thận lupus IV & 4 & 12,5 \\
\hline Viêm thận lupus V & 1 & 3,1 \\
\hline IgA & 4 & 12,5 \\
\hline Viêm cầu thận hậu nhiễm & 1 & 3,1 \\
\hline Tổng & $\mathbf{3 2}$ & $\mathbf{1 0 0}$ \\
\hline
\end{tabular}

(*) FSGS (focal segmental glomerulonephritic sclerosis): xơ hoá cầu thận từng phần khu trú; MPGN (membranoproliferative glomerulonephritis): viêm cầu thận tăng sinh màng), $\mathrm{MCD}$ : minimal change disease.

Tổn thương tối thiểu thường phù hợp với hội chứng thận hư chiếm tỉ lệ nhiều nhất (46,9\%), tiếp đến là các type lupus ban đỏ hệ thống (viêm thận lupus type IV chiếm tỉ lệ cao 12,5\%).

\subsection{Mối tương quan giữa lâm sàng và kết quả giải phẫu bệnh}

Bảng 7. Mối tương quan giữa lâm sàng và kết quả giải phẫu bệnh

\begin{tabular}{|c|c|c|c|c|c|c|c|}
\hline Kết quả & HCTHKC & $\begin{array}{c}\text { HCTHP } \\
\mathrm{T}\end{array}$ & $\begin{array}{c}\text { Lupus } \\
\text { ban đỏ }\end{array}$ & $\begin{array}{c}\text { Đái máu } \\
\text { tái diễn }\end{array}$ & $\begin{array}{c}\text { VCTC } \\
\text { đái máu } \\
\text { đại thể }\end{array}$ & $\begin{array}{c}\text { VCTC } \\
\text { suy thận }\end{array}$ & $\begin{array}{c}\text { Suy } \\
\text { thận } \\
\text { CRNN }\end{array}$ \\
\hline MCD & 8 & 3 & 0 & 3 & 1 & 0 & 0 \\
\hline FSGS & 3 & 0 & 0 & 0 & 0 & 0 & 0 \\
\hline MPGN & 0 & 0 & 0 & 0 & 1 & 0 & 0 \\
\hline $\begin{array}{c}\text { Xơ hóa } \\
\text { toàn bộ }\end{array}$ & 0 & 0 & 0 & 0 & 0 & 0 & 1 \\
\hline VTLupus III & 0 & 0 & 2 & 0 & 0 & 0 & 0 \\
\hline VTLupus IV & 0 & 0 & 4 & 0 & 0 & 0 & 0 \\
\hline VTLupus V & 0 & 0 & 1 & 0 & 0 & 0 & 0 \\
\hline IgA & 0 & 1 & 0 & 1 & 1 & 1 & 0 \\
\hline $\begin{array}{c}\text { VCTC hậu } \\
\text { nhiễm }\end{array}$ & 0 & 0 & 0 & 0 & 0 & 1 & 0 \\
\hline
\end{tabular}

(*) HCTHKC: Hội chứng thận hư kháng corticoid; HCTHPC: hội chứng thận hư phụ thuộc corticoid; VCTC: viêm cầu thận cấp; CRNN: chưa rõ nguyên nhân. FSGS (focal segmental glomerulonephritic sclerosis): xơ hoá cầu thận từng phần khu trú; MPGN (membranoproliferative glomerulonephritis): viêm cầu thận tăng sinh màng); $\mathrm{MCD}$ : minimal change disease; VT: viêm thận.
Trong 15 trường hợp bệnh thận tổn thương tối thiểu có $11 / 15(73,3 \%)$ là hội chứng thận hư. $3 / 32$ trường hợp tổn thương xơ hóa cầu thận từng phần khu trú (FSGS).

Tổn thương bệnh thận IgA gặp trong đái máu đại thể tái diễn, đái máu đại thể kéo dài và viêm cầu thận có suy thận.

Có sự tương đồng giữa lâm sàng và kết quả sinh thiết thận. 


\section{BÀN LUẬN}

Trong nghiên cứu của chúng tôi, độ tuổi trung bình $10,28 \pm 3,06$, nhỏ nhất 4 tuổi và lớn nhất 15 tuổi. Theo nghiên cứu của tác giả Mayerly Prada Rico (2018) tuổi trung bình sinh thiết 11 tuổi [8], và tác giả Neşe Özkayın(2016) là 9,62 $\pm 4,26$, tương đương nghiên cứu chúng tôi[9]. Nhóm tuổi được sinh thiết chiếm tỉ lệ cao nhất là 11-15 tuổi chiếm $50 \%$ và thấp nhất là nhóm dưới 5 tuổi kết quả này phù hợp với nghiên cứu của tác giả Shin Ae Lee (2017) là 41,2\%[11].

Về giới tính, tỉ lệ nam $(65,5 \%)$ cao hơn nữ $(34,3 \%)$, tỉ lệ nam:nữ là $1,9: 1$. Kết quả này tương đương với các nghiên cứu của Shin Ae Lee (2017) 1,8:1[11].

Biểu hiện lâm sàng trong bệnh lý cầu thận rất khác nhau từ không có triệu chứng đến triệu chứng rất nặng. Theo kết quả nghiên cứu của chúng tôi, phù vẫn là dấu hiệu thường gặp nhất chiếm tỉ lệ $75 \%$, tiếp đến là triệu chứng tăng huyết áp $31,3 \%$ và liên quan đến đái máu $28,1 \%$. Điều này là phù hợp với $\mathrm{y}$ văn với phù thường gặp 75\% trong viêm cầu thận cấp, $100 \%$ trong hội chứng thận hư. Về tăng huyết áp, theo nghiên cứu của Shin Ae Lee,tỉ lệ tăng huyết áp trong hội chứng thận hư là $15,7 \%[12]$.Chẩn đoán lâm sàng trước sinh thiết chiếm tỉ lệ cao nhất là hội chứng thận hư chiếm 46,9\%, tiếp đến là lupus ban đỏ chiếm $21,9 \%$. Kết quả này phù hợp với nghiên cứu của Pawan P.M với tỉ lệ hội chứng thận hư là $77,9 \%[10]$.Về chỉ định sinh thiết thận và kết quả sinh thiết:

- Các nghiên cứu trước đây đều ghi nhận hội chứng thận hư là chỉ định phổ biến của sinh thiết thận [6]. Nhận định này cũng phù hợp kết quả của chúng tôi, tỉ lệ bệnh nhân hội chứng thận hư được sinh thiết $46,9 \%$ trong đó có $34,4 \%$ thận hư kháng corticoid và $12,5 \%$ thận hư phụ thuộc corticoid. Tiếp đến là lupus ban đỏ chiếm $21,9 \%$. Kết quả này cũng khá tương đồng với nghiên cứu của Huỳnh Thoại Loan (2010) là 44,6\% trong đó thận hư kháng corticoid chiếm $68,3 \%$ [3].

- Thực tế lâm sàng, hộichứng thận hư có thể có liên quan với các nhóm type khác nhau của viêm cầu thận do đó môbệnh là rất cần thiết để chẩn đoán và điều trị phù hợp. Dựa vào kết quả sinh thiết thìtổn thương tối thiểu vẫn là sang thương thường gặp nhất của hội chứng thận hư chiếm 11/15 (73,3\%). Kết quả này tương đương nghiên cứu của Shin Ae Lee 2017 tỉ lệ sàng thương tối thiểu là 70,3[12]. Tuy nhiên, xơ hóa cầu thận khu trú từng phần (FSGS)trong nghiên cứu của chúng tôi chỉ chiếm $9.4 \%$, khá thấp so với nghiên cứu của tác giả Huỳnh Thoại Loan là 23,66\% [3]. Giải thích điều này có thể do cỡ mẫu trong nghiên cứu của chúng tôi còn thấp.

- 1 trường hợp hội chứng thận hư phụ thuộc corticoid sinh thiết kết quả bệnh thận IgA. Tỉ lệ này thấp hơn so nghiên cứu của tác giả Huỳnh Thoại Loan với $25 \%$ trường hợp IgA trên bệnh nhi hội chứng thận hư phụ thuộc corticoid[3].

- Chúng tôi có 4 trường hợp đái máu sinh thiết ra tổn thương tối thiểu chiếm tỉ lệ $12,5 \%$, trong đó 3 trường hợp đái máu tái diễn, 1 trường hợp đái máu đại thể kéo dài. Theo tác giả White, $13 \%$ đái máu sinh thiết có tổn thương tối thiểu khá phù hợp kết quả chúng tôi [13].

- Ngoài ra, chúng tôi có 3 trường hợp sinh thiết ra bệnh thận IgA trong đó có 1 trường hợp là đái máu tái diễn, 1 trường hợp đái máu đại thể kéo dài và 1 trường hợp viêm cầu thận tiến triển nhanh. Điều này khá hợp lý với nghiên cứu tác giả Huỳnh Thoại Loan với kết quả $50 \%$ trường hợp bệnh thận $\operatorname{IgA}$ có biểu hiện lúc chẩn đoán là tiểu máu đại thể[3].Chỉ 1 trường hợp đái máu đại thể kéo dài sinh thiết ra tổn thương viêm cầu thận tăng sinh màng chiếm tỉ lệ $3,1 \%$.

- Về lupus ban đỏ, chúng tôi có 7 bệnh nằm trong chỉ định sinh thiết chiếm tỉ lệ $21,9 \%$ và kết quả là 2 bệnh viêm thận Lupus nhóm III, 4 bệnh Lupus nhóm IV và 1 bệnh thận Lupus nhóm $\mathrm{V}$. Theo nghiên cứu của tác giả Shin Ae Lee 2017 tỉ lệ viêm thận lupus sinh thiết khá thấp chỉ $1,5 \%$ và tác giả Adela Arapovic 2020 là 1,9\%[1], [12], điều này có thể do sự khác biệt về địa dư và số liệu trong nghiên cứu của chúng tôi còn hạn chế.

- Chúng tôi có 1 trường hợp sinh thiết thận trên bệnh suy thận chưa rõ nguyên nhân có kích thước thận bình thường và kết quả sinh thiết về xơ hóa cầu thận toàn bộ (trên nền 
FSGS thể không đặc hiệu) giúp khẳng định chẩn đoán suy thận mạn trên bệnh nhi.

Ngoài ra 2 trường hợp viêm cầu thận có suy thận có chỉ định sinh thiết thận thì một trường hợp là bệnh thận $\operatorname{IgA}$ và 1 trường hợp là viêm cầu thận cấp hậu nhiễm.

Dựa vào bảng 7 chúng tôi nhận thấy có sự phù hợp giữa bệnh cảnh lâm sàng và kết quả sinh thiết thận. Tuy nhiên vì cỡ mẫu trong nghiên cứu còn nhỏ nên cần có nhiều nghiên cứu khác lớn hơn về vấn đề này.

\section{KẾT LUẬN}

Từ kết quả sinh thiết thận cho 32 bệnh nhi có bệnh lý cầu thận chúng tôi rút ra một số kết luận sau:

- Chỉ định sinh thiết thận phổ biến là hội chứng thận hư kháng corticoid 34,4\%.

- Tổn thương mô bệnh học thường gặp nhất là tổn thương tối thiểu $(46,9 \%)$.

- Nhìn chung có sự phù hợp giữa lâm sàng các bệnh cầu thận và tồn thương mô bệnh học trên sinh thiết thận.

\section{TÀI LIỆU THAM KHẢO}

1. Adela Arapović et al (2020), "Epidemiology of 10-year paediatric renal biopsies in the region of southern Croatia",BMC Nephrology (2020) 21:65.

2. Ingelfinger JR, Kalantar-

Zadeh K, Schaefer F, "World kidney day 2016: Averting the legacy of kidney disease--focus on childhood", Am J Kidney Dis 67: 349-354

3. Huỳnh Thoại Loan (2010), "Sinh thiết thận tại Bệnh viện Nhi Đồng 1", Y học thực hành (739)- số 10/2010, tr 99-104.

4. Jannette JC, Olson JL, Schwartz MM, et al (2007), Heptinstall's Pathology of the kidney. 2007
5. Kishore Phadke et al (2014), "Evaluation of Renal Disease", Manualpediatric nephrology, Springer, pp: 34-35.

6. Lanewala A, Mubarak M, Akhter F, Aziz S, Bhatti S, Kazi JI. Pattern of pediatric renal disease observed in native renal biopsies in Pakistan. J Nephrol 2009;22:739-46

7. Maarten W. Taal et al (2012), "Diseases of kidney and urinary tract in children", Brenner \& Rector's The Kidney $9^{\text {th }}$ version, pp:2639-2640

8. Mayerly Prada Ric et al (2017), "Characterization and Etiopathogenic Approach of Pediatric Renal Biopsy Patients in a Colombian Medical Center from2007-2017, International Journal of Nephrology , Volume 2018, Article ID 9603453.

9. Neşe Özkayın (2016), “Assessment of Ten-Year-Long Results of Kidney Biopsies Performed on Children in the Thrace Region of Turkey", Balkan Med J ;33:589-93

10. Pawan Pradeep Mutalik et al (2015), "Clinico-pathological correlations of childhood glomerular disease in Eastern India", Sri Lanka Journal of Child Health; 44(1): 31-371

11. Ramesh Khanna (2011), "Clinical Presentation \& Management of Glomerular Diseases: Hematuria, Nephritic \& Nephrotic Syndrome", Missouri Medicine | January/February 2011

12. Shin Ae Lee, Min Sun Kim, Soon Chul Kim, Dae-Yeol Lee (2017), "Clinical and Pathological Findings of Renal Biopsy in Children: Outcomes from a Single Center Over 27 Years", Child Kidney Dis;21:8-1. 